\title{
EDUCAÇÃO E IMPRENSA: A ESCOLA COMO INSTRUMENTO IDEOLÓGICO
}

\author{
Claudia Maria Petchak Zanlorenzi ${ }^{1}$ \\ Maria Isabel Moura Nascimento ${ }^{2}$
}

\begin{abstract}
RESUMO
O presente artigo, parte de uma pesquisa de doutorado, tem por finalidade apresentar a análise realizada na revista $A$ Escola, Revista do Grêmio dos Professores Públicos do Estado (1906-1910), especificamente sobre o modelo de trabalhador docente, discutindo sobre a tolerância e a resignação veiculadas nas folhas deste periódico, ao tratar do trabalho do professor. $\mathrm{O}$ artigo está dividido em dois momentos, nos quais primeiramente será apresentada a revista $A$ Escola e na sequência serão apontadas as reflexões sobre a temática tendo como fonte os excertos da referida revista. As reflexões que suscitam do estudo na revista A Escola, apontam os discursos, os anseios, as conveniências, os interesses da sociedade em relação à educação, fornecendo pistas sobre as repercussões e polêmicas instauradas, e mais, contribuindo sobremaneira para a compreensão das situações da contemporaneidade Os resultados desse estudo permitem concluir que a educação no estado do Paraná, no início do século XX, foi marcada pela influência da ideologia liberal, e essa foi amplamente disseminada nas folhas da Revista A Escola.

Palavras-chave: Liberalismo. Educação. Revista Pedagógica. Trabalho docente. Revista $A$ Escola.
\end{abstract}

\section{EDUCATION AND PRESS: SCHOOL AS IDEOLOGICAL INSTRUMENT}

\begin{abstract}
This study is part of a $\mathrm{PhD}$ research. It aims to present the analysis about teaching model presented in the journal The School, the journal from the State Public Teachers College (1906-1910), by discussing tolerance and resignation conveyed in this periodical pages, in dealing with the teacher's work. The essay is divided into two stages: first of all, it presents The School journal, and following it will point impressions on the subject by using some excerpts from the journal as sources. The reflections that raise from this research point the speeches, the desires, the conveniences, the interests of society about education. They provide clues about the repercussions and controversies that have been brought, and more, greatly they contribute to the understanding of contemporary situations. The results of this study allowed us to conclude that the education in Paraná had been marked by the influence of liberal ideology in the early twentieth century, and that it had been widespread in The School journal pages.
\end{abstract}

Keywords: Liberalism. Education. Pedagogical journal. Teaching. The School. 


\section{Introdução}

Gerir a desigualdade social explícita na sociedade capitalista é uma das finalidades que a ideologia liberal é chamada a cumprir por meio de instrumentos mais sofisticados, como a educação e a imprensa. Sob esta perspectiva, a revista A Escola ${ }^{3}$, Revista do Grêmio dos Professores Públicos do Estado do Paraná ${ }^{4}$, publicada entre 1906 a 1910, não foge dessa regra. Defende-se que a revista A Escola foi instrumento de disseminação da ideologia liberal e, como órgão de formação docente, vislumbrou-se que esta ideologia chegaria até os bancos escolares via trabalho do professor.

A carência de escola para a formação de professores, no início do século XX, possibilitou outros meios de formação, destarte a Revista A Escola tornou-se um instrumento eficaz e rápido para a ampla divulgação dos ideais propostos para a sociedade capitalista. Ao homogeneizar o trabalho de uma categoria profissional e uniformizar o discurso pedagógico, cumpria a função de ser [...] o elo cohesivo dos professores (VELLOZO, 1906, p. 119), fato que estabelecia as características da revista, que [...] só pode ser uma revista didática (VELLOZO, 1906, p. 119), ou melhor, um modelo a ser seguido, [...] de acordo com os dados da Pedagogia Hodierna ${ }^{5}$ (VELLOZO, 1906, p. 119).

$\mathrm{O}$ presente artigo, parte de uma pesquisa de doutorado, tem por finalidade apresentar a análise realizada na revista $A$ Escola, especificamente sobre o modelo de trabalhador docente, discutindo sobre a tolerância e a resignação veiculadas nas folhas deste periódico, ao tratar do trabalho do professor.

O artigo está dividido em dois momentos, nos quais primeiramente será apresentada a revista $A$ Escola e na sequência serão apontadas as reflexões sobre a temática tendo como fonte os excertos da referida revista.

\section{Revista A Escola, do Grêmio dos Professores Públicos do Estado do Paráná.}

A revista A Escola, que iniciou sua impressão em 1906 e terminou em 1910, destinava-se aos professores e era expressão de um grupo restrito de professores, "[...] uma parcela da elite letrada local, que se propunha encaminhar a população brasileira ao progresso e ao desenvolvimento moral, intelectual e econômico" (MARACH, 2007, p. 13). A comissão editorial era composta pelo presidente do Grêmio, Julio Theodorico Guimarães, o primeiro secretário Veríssimo de Souza, segundo secretário Lourenço de Souza e, como tesoureiro, Brazilio da Costa. Na direção, teve Sebastião Paraná e Dario Velozo, sendo que o primeiro dirigiu as seis primeiras edições (MARACH, 2007).

Estritamente direcionada aos professores, não havia nenhuma alusão a artigo para pais de alunos ou comunidade, compunha-se de artigos de opinião de diversos autores, sessões com explicações de língua portuguesa, língua estrangeira (francês), matemática, poesias, cartas, notícias relacionadas à educação paranaense e do país. Sem um editorial específico, a primeira página era reservada a vários autores, que poderiam ser ou os componentes do Grêmio ou o responsável pela revista ou um educador renomado.

Era reservado um espaço na revista para os relatórios de professores, realizados em "[...] conformidade com o que preceitua o artigo n. 62 (sic), n. 11, do Regulamento de Instrucção Pública do Paraná ${ }^{6}$ " (A ESCOLA, 1906, p. 17). Publicava-se ainda o expediente oficial com decretos do governo e, no final, uma seção permanente, que incluía uma descrição com os nomes dos professores e localidades das cadeiras promíscuas ${ }^{7}$ e suburbanas das escolas públicas da capital, dos estabelecimentos de ensino particulares, dos responsáveis pela instrução pública do estado e os componentes da diretoria do Grêmio dos Professores Públicos do Estado do Paraná. 
A revista teve dois momentos problemáticos distintos em sua circulação. $\mathrm{O}$ primeiro, com a busca financeira, concretizada em 1907, quando "[...] o Dr. Candido, digno presidente do Estado, destinou subsídios para o auxílio à publicação de 'A Escola'," (ESCOLA, 1907, p. 144), com uma publicação de frequência mensal ${ }^{8}$; e o segundo, com a deposição, em 1908, de João Cândido do cargo de governador, por Francisco Xavier, período em que a revista não teve mais o auxílio financeiro do governo, o que a levou a ter um teor mais oposicionista, conforme nota no número 1, 1909, p. 4: “[...] a Diretoria do Grêmio de Professores resolveo prosseguir a publicação de A Escola, mesmo sem a subvenção do Estado", assim como solicitar, com mais veemência, o pagamento das assinaturas. Sua publicação, desde então, variava, ora bimestral, ora semestral, e sua edição foi encerrada em 1910, "[...] atacada de anemia ou algibeirite porque sem assinaturas, sem aussilios senao dos membros do Grêmio dos Professores" (BRAGA, 1910, p. 349- grifos do autor).

Os intelectuais ${ }^{9}$ e professores à frente da revista, "[...] em prol das ideas liberais" (PARANÁ, 1906, p. 135), representavam a classe social dominante e detinham os instrumentos de conhecimento, ou seja, os meios de produção intelectual, a propriedade intelectual e, particularmente, possuíam interesses peculiares à sua classe social, garantindo a subordinação entre eles - dotados de propriedade intelectual - e os professores, além da perpetuação dos privilégios de classe.

Nesse momento, a escolarização era tratada por homens públicos e por intelectuais que, ao mesmo tempo, eram "educadores", num tempo em que os assuntos educacionais não constituíam, ainda, uma a atividade suficientemente profissionalizada. Apenas na década final da Primeira República a situação vai ser alterada, com o aparecimento do "técnico" em escolarização, a nova categoria profissional [...] (NAGLE, 2009, p. 117).

O conteúdo que era proposto pelos ditos guias esclarecidos, ou melhor, figuras profissionais capazes e impregnadas de "espírito burguês" (CAMBI, 1999, p. 408), caberia aos demais professores reproduzir de forma acrítica, sem questionamentos. Vê-se na formação do trabalho docente a finalidade da nova educação burguesa, qual seja a incumbência de "[...] reservar para o homem das classes superiores o completo desenvolvimento do espírito" (PONCE, 2001, p. 170), já que ele, com seu esforço, conseguiu a propriedade intelectual. Esta premissa sustenta-se na ideia de igualdade natural entre os homens e cada um apropria-se e relaciona-se com a natureza de formas diversas, o que marca a individualidade. No entanto

É somente graças à riqueza objetivamente desenvolvida da essência humana que a riqueza da sensibilidade humana subjetiva é em parte cultivada [...]. A formação dos cinco sentidos é um trabalho de toda a história universal até nossos dias. (MARX, 1991 p. 172).

Segue-se o princípio de que as ideias são construídas e a mente é como "[...] papel em branco, desprovida de todos os caracteres, sem quaisquer ideias [...]" (LOCKE, 1991, p. 27) ${ }^{10}$. Assim, a formação do indivíduo, neste caso a formação do professor, é primordial para a reprodução da ideologia, em que o consenso e a conformação dariam sustentação para a premissa de que, de acordo com a atuação do indivíduo, há limites e possibilidades, ou seja, há o merecimento, dado o esforço de ter a propriedade intelectual. No entanto, “[...] não se julga um indivíduo pela ideia que ele faz de si próprio [...]; é 
preciso, pelo contrário, explicar esta consciência pelas contradições da vida material [...]" (MARX, 1983, p. 25).

Os profissionais que atuavam na revista justificavam a sua publicação com a afirmação de que os professores tinham o "[...] desejo ardente de aperfeiçoar-se mais $e$ mais" (MACEDO, 1906, p. 10-11) e de que seus objetivos eram de "[...] trabalhar esforçadamente pela instrucção da infancia e pela moral da classe dos seus educadores [...], certos de que, além disso, prestariam "[...] serviços de real valia ao progredimento $e$ prosperidade do nosso querido Estado do Paraná” (A ESCOLA, 1906, p. 76). O impresso foi uma forma efetiva e eficaz de manutenção dos ideais liberais desse grupo, ecos da sociedade brasileira do início do século XX e, "[...] como instrumento veiculador e manipulador está, portanto, destinado a atuar na vida social" (ARAÚJO, 2002, p. 97), na ressonância das temáticas abordadas e dos valores veiculados.

Por ser uma revista didática, seu objetivo era formação do professor, destinada a "[...] despertar os ânimos, a discutir e vulgarizar os bons ensinamentos da sociologia" (PARANÁ, 1906, p. 2), num esforço para que “[...] os ensinamentos pedagógicos se diffundam pela coletividade, orientando os velhos mestres e provocando as vocações latentes de mestres novos que hão de vir (MACEDO, 1906, p. 11). Como se tratava de um meio rápido e imediato de convencimento e de coesão do trabalho docente, a revista não era apenas um veículo de informação pedagógica, mas um mecanismo de propagação de ideias, um canal de representação e ao mesmo tempo de regulação que, sutilmente, vinculava um sistema de ideias de como o real deveria ser compreendido e aceito no estado do Paraná. Era uma revista semelhante a outras revistas que agiam em outros estados, formando assim uma cadeia.

Nas folhas da revista, a Escola, em seu sistema de ideias, “[...] aparato que a prática burguesa desenvolve em seu processo de consolidação e expansão" (VALDEMARIN, 2000, p. 35), tinha por finalidade a concretização e a legitimação da ordem capitalista, pela noção de liberdade individual. Tal defesa era necessária para a atividade econômica e todo o postulado consequente de tal ordem, como o direito de propriedade e a livre iniciativa, estendidos também a outros termos, como liberdade de expressão, de pensamento, organização política (VALDEMARIN, 2000, p.32), além de chanceladas nas letras da lei quando se propõe o direito a ter direitos.

Pretendendo-se a ampliação do poder de inculcação do convencimento de que todos têm direitos a ter direitos, garantidos legalmente, este sistema de ideias inculcava que todos são igualmente livres para o acesso à propriedade na medida de seu esforço próprio. É sob a premissa deste ideal que se organiza o ensino que será ministrado na escola, bem como a formação do professor, que será o disseminador desse ideário no Brasil, em especial no início do século XX, com o novo regime, "[...] espaço adequado à escolarização em massa e às necessidades da universalização popular" (SOUZA, 2006, p. 36).

Ao defender a ideia de um ensino moderno e inovador, de conteúdos que possibilitariam a manipulação ideológica e apresentar a escola como uma via de ascensão na escala social, adequava-se a escola às necessidades do contexto, bem como, concomitantemente, promovia-se a aceitação dos valores vigentes na sociedade capitalista, entre eles a meritocracia e as condições precárias em que viviam muitos dos indivíduos considerados como naturalmente incapazes, já que "la felicidad y la desgracia del hombre son, en grande parte, su própria obra"11 (LOCKE, 1986, p. 31). Atribuía-se um caráter natural à igualdade entre os indivíduos e, ao mesmo tempo, explicava-se a diferença como residindo na capacidade de trabalho que cada um exerce por esforço próprio, tendo como resultado a propriedade - nesse caso, a intelectual. 
Merece destaque a presença da ideologia liberal no trabalho do professor e em sua formação, tendo como finalidade a exigência de um novo modelo de professor e de trabalho docente. Daí a necessidade de um professor resignado e, ao mesmo tempo, pronto para acreditar no que era proposto. Enaltecia-se a profissão, igualando-a a algo abstrato e messiânico e considerando a educação formal como antídoto para os problemas daquela sociedade e alavanca para o progredimento. Temas estes explorados frequentemente na revista A Escola.

\section{O modelo de trabalhador docente: a tolerância e a resignação}

É na formação docente que é possível entrever a ideologia que delineia os projetos educacionais, em virtude de que estes direcionam, por intermédio dos métodos, dos conteúdos, da avaliação e dos manuais didáticos, o trabalho do professor, induzindo-o à aceitação da mesma. As concepções do trabalho docente nos diferentes contextos históricos proporcionam o entendimento das propostas de formação dos profissionais de educação, especialmente por ser um espaço para a disseminação de ideias, valores, enfim, da ideologia. A transformação ou a concretização de uma ideologia em prática pedagógica, assim como a sua defesa não se resumem a uma técnica, mas sim, como já foi afirmado acima, a uma concepção de sociedade, de homem e de educação. Para o contexto em estudo, objetivava-se formar o professor para o processo de ensino e aprendizagem, no qual a classe que usufruía essa escola pública e que tivesse propriedade continuaria a ocupar o lugar em sua classe, já os demais teriam uma qualificação para o processo produtivo capitalista, visto não haver interesse de se alterar a estrutura básica das relações econômicas e sim mantê-las.

Para o alcance deste objetivo, as formas de inculcação ideológica foram determinantes, destinadas ao esvaziamento do conteúdo de formação do trabalhador docente, valendo-se da obediência aos ditames da sociedade capitalista, que supostamente apregoava valores democráticos. Pela defesa da ampliação do aparelho escolar, sutilmente aumentavam-se a abrangência e a exposição aos valores que contribuiriam para reprodução da hegemonia existente. É em meio a esses objetivos que se organizou a formação desse professor.

O modelo ideal de trabalhador docente que deveria ser internalizado pelos professores, no início do século XX, seduzidos pelo discurso de partícipes da construção da nova sociedade, seria o de respeitável sacerdote: “[...] dynamitisado por energias masculas, efervorado do mais intenso desejo de bem fazer, propellido pelos dictames de uma consciência perseverante ajustada á retilinea do bem" (SOUZA, 1906, p. 3). Por trás desse modelo estava o interesse na imobilidade desse trabalhador que, ao condicioná-lo aos aspectos morais, levava-o a aderir aos ideais propostos para aquela sociedade.

O professor, em seu processo de formação, era envolto pelo mito de devoção, haja vista que o ensino apresentava-se como "[...] um sacerdócio magno e o professor como um respeitável sacerdote que deve estar aparelhado, moral e intellectualmente [...]" (GOMES, 1909, p. 26). Consequentemente, não se configurava a visão do professor como uma realidade histórica e atuante na sociedade, já que sua função transcendia à concreticidade instaurada nas relações materiais. Como

"[...] gralhas, os professores vestem-se de penas de pavão ao acreditar que seu trabalho tem um caráter cívico, de constituição de uma nação, do progresso do qual seriam legítimos porta-vozes" (VALLE, 1997, p. 133). 
Difundia-se a ideia de que o professor deveria ser desprovido de qualquer interesse de maiores bens materiais "[...] um exemplo de virtudes" (PARANÁ, 1906, n. 2, p. 11), enaltecendo a importância do seu trabalho, posto tratar-se de uma vocação sublime. Eis seu retrato:

[...] modesto e despretensioso, vae o professor primário cumprindo, sem arruídos nem apparato, o seu alto ministério de instrucção, de civismo e de amor, contribuindo assim eficazmente para a concretização do ideal formoso da grandeza e felicidade da pátria (SOUZA, 1906, p. 4).

Os professores, mesmo no estado laico, onde o "[...] ensino deve ser obrigatoriamente leigo [...]", afastando da escola, "[...] onde se educam os cidadãos de amanham, a moral sectaria (qualquer que seja a religião) [...]” (VELLOZO, 1907, p. 148), contraditoriamente seriam os sucessores seculares do sacerdote e abnegados exerceriam suas funções no "templo de uma única religião [...]" (CORREIA, 1909, p. 105), a escola. Monarcha (1999) caracteriza com maestria e perspicácia como se dava a transposição do estado religioso para o laico na escola: local onde o "[...] clero científico deve conduzir seus acólitos à Cidade da Luz, versão secularizada da Cidade de Deus e situada em lugar nenhum" (MONARCHA, 1999, p. 228).

A conservação desta indumentária em relação ao papel do professor apresenta o lado contraditório do liberalismo e de seus preceitos, o que é típico desta ideologia para ser mantida hegemônica. Neste caso, o princípio da tolerância mostra o lado conservador da ideologia liberal, porque, ao mesmo tempo em que prega a aceitação dos valores democráticos vigentes da sociedade republicana para aquele profissional aberto às mudanças, às diferentes opiniões individuais e que formaria o "novo" cidadão para a pátria, ao compará-lo ao sacerdote, implicitamente, colocava-o como tolerante ao seu papel de abnegado e omisso, visto que suportaria os seus desígnios sem arruídos e sem ameaçar a ordem. Era uma forma de por um limite nesse trabalhador e no avanço das organizações dos demais trabalhadores, ou seja, uma forma orquestrada de repressão ao se propor um modelo verticalizado de sacerdote como ideal, aceitando inclusive a religião como referência.

Não é a diversidade de opiniões (o que não pode ser evitado), mas a recusa de tolerância para com os que têm opinião diversa, o que se poderia admitir que deu origem à maioria das disputas e guerras que se têm manifestado no mundo cristão por causa da religião (LOCKE, 2007, p. 24).

Destarte, a propagação da ideia de tolerância à vocação sublime e de indivíduo dotado de aspirações morais foi ideologicamente salutar. O professor, ao seguir esta ordem, receberia

[...] uma recompensa mais valiosa que a celebridade histórica: a consoladora approvação de sua consciência, compensativa de todos os esforços e sacrifícios, premio melhor que todos os estímulos, superior a todos os applausos e maior que todos os louvores (SOUZA, 1906, p. 5).

O enaltecimento da profissão e a idealização do trabalho do professor, relacionados a uma missão, à benevolência, utilizando-se de acepções abstratas e sem um real 
entendimento da sua função como trabalhador da sociedade capitalista, contribuiriam para o convencimento e conformação desse profissional, ou melhor, contribuiria para a homogeneização e a uniformização de um modelo para aqueles que iriam formar o trabalhador livre. Não só se confere o caráter de importância de seu trabalho, como se deposita a responsabilidade para se alcançar o fim proposto: o progresso. Para tanto,

Aos educadores será commettida pelo porvir, que já vem alvorejando no horisonte, a missão grandiosa de inaugurar uma era promissora de luz, nuncia de resultados beneficissimos para o evolucionamento das hordiernas collectividades (COSTA, MOREIRA, SOUZA, 1910, p. 126).

Ao entender o professor como construtor da civilização, posto que "[...] portador de uma nobre missão civilizadora e patriótica" (SOUZA, 2006, p. 70), pressupõe-se que essa sociedade deveria ser reorganizada, ademais, estava-se sob um novo regime e sob um novo modo de produção e os valores advindos deles deveriam ser legitimados e aceitos. "Era pelo professor que se poderia reformar a escola e levá-la a realizar as grandes finalidades da educação pública" (SOUZA, 2006, p. 70), assim nada mais eficaz do que o mestre, sujeito de sabedoria e autoridade, participante direto da instrução pública, chancelar a ideologia que asseguraria "[...] efficazmente para a concretização do ideal formoso da grandeza e felicidade da pátria" (SOUZA, 1906, p. 4). O professor também deveria ser convencido do seu "[...] papel regenerador ${ }^{12}[. .$.$] ", qual seja, gerar ideologicamente a$ visão do trabalhador livre, o novo homem para a sociedade republicana, para a nova Nação, com os conhecimentos necessários para a sociedade capitalista, "[...] apparelhado, moral e intelectualmente" (GOMES, 1909, p. 26).

Visto que o desenvolvimento intelectual está diretamente relacionado às questões materiais, na qual a exploração tem um peso elevado, assim como a desigualdade é entendida como natural e como incentivo para a competição, tornava-se difícil o desenvolvimento de uma visão consciente e, consequentemente, um trabalho docente desenvolvido intelectualmente, e sim uma formação docente que contribuiria para a hegemonia da ideologia liberal, adequando-se às circunstâncias desse contexto apenas mediante retoques, a partir de reformas. Assim, predomina a exaltação dos aspectos morais sobre os intelectuais, por isso o trabalho do professor não deveria ser julgado apenas ao cumprir "[...] os seus deveres ensinando os alumnos a ler e escrever [...], ao contrário, "a sua missão transcende, posto que espinhosa, vai além" (PARANÁ, 1906, p. 2), qual seja, a "[...] santa missão de illuminar o espírito" (COSTA, 1906, p. 172) e, ao mesmo tempo, "[...] no que respeita á ampla liberdade espiritual, á emancipação do ensino, seguindo o espírito do novo regimen político" (C. P., 1906, p. 95).

Ao direcionar o trabalho docente para os aspectos morais, não seria apenas uma questão de prevalência de um aspecto sobre o outro, mas de perpetuar a desigualdade que mantém a sociedade capitalista, colocando-a como desigualdade natural, portanto, inútil e impossível tentar descartá-la. Vale lembrar que "[...] a desigualdade dos conhecimentos é um meio de manter todas as desigualdades sociais [...]" (MARX, ENGELS, 1979, p. 38, NT), justificando-se que não se trata de acabar com as diferenças e sim adaptar-se a elas (LOCKE, 1986), já que a todos foi dada a razão para que a utilizassem para maior proveito da vida.

Como invenção da tradição ${ }^{13}$, ou seja, inculcação de ideias com outras indumentárias, fundamentada na ordem natural de que não é possível combater o que não se pode mudar, essa visão de professor auxiliou na disseminação da justificativa para a desigualdade instaurada na sociedade, tendo como objetivo incorporar valores que 
legitimassem a ideia de condição natural, dom, vocação e universalização de propriedade e, ao mesmo tempo, contraditoriamente, a ideia de meritocracia e de convencimento da própria incapacidade do indivíduo. "Esse novo passado inventado legitima o momento atual, descaracterizando as brutais desigualdades existentes como algo natural que sempre esteve aí [...]" (DIAS, 2007, p. 119).

A igualdade de oportunidade é reinventada, nesse caso do professor, como competência para utilizar de forma diferente as oportunidades que a sociedade lhe oferece, conforme a sua condição, fundamentando, assim, a meritocracia com status científico. Não se utilizavam mais afirmações abstratas, como, por exemplo, o ideal divino, e sim a praticidade da ação humana, professada cientificamente pelas teorias de conhecimento, nesse caso o empirismo, que se fundamentava no processo de aprendizagem e tinha seus desdobramentos nos processos educativos que envolvem tanto o aprender como o ensinar.

Para além da visão do trabalho docente considerado como missão, dom, sacerdócio, predomina a imagem messiânica do professor com "[...] a missão grandiosa de inaugurar uma era promissora de luz, nuncia de resultados beneficissimos para o evolucionamento das hordiernas collectividades" (COSTA, MOREIRA, SOUZA, 1910, p. 126). Foi uma forma de legitimar a ideologia liberal, uma vez que, considerado como trabalho não material, o consumo seria imediato e a ideologia propagada de forma rápida.

Enaltecer e dignificar o trabalho desse profissional, representando-o como imprescindível para o progredimento da nação, era um meio de seduzi-lo e convencê-lo de que, pela educação, o país rumaria ao "nível do século", à modernidade e à riqueza.

A função do mestre só deve ser entregue a competentes que não façam jus apenas ás renumerações do Estado, mas que sejam funcionários, conscientes da missão que lhes é dada desempenhar, a bem da pátria e da humanidade. Ao mestre-escola compete dedicar-se inteiramente á sua missão de instruir para alcançar o fim: educar. Estas duas faces da educação em geral se completam perfeitamente (A ESCOLA, 1910, p. 127).

$\mathrm{Na}$ ilusão messiânica de ser missionário do ensino e resignado, o trabalhador docente era formado para que exercesse seu trabalho sem enfrentamento, ou melhor, que não percebesse a exploração a que estava submetido, perpetuando essa mesma resignação na preparação bem dosada e difundida pela escola, um procedimento refinado e orquestrado para que não se corresse "[...] o perigo de que o professor tomasse consciência de que ele é um operário como os outros, explorado e humilhado" (PONCE, 2001, p. 181). Trata-se de um paradoxo - conservador no liberal - que se concretiza ao ser transferido a algo que transcende o social - algo superior, além da materialidade - como um movimento natural, pairando acima da vontade individual.

Tal convencimento levaria à alienação ${ }^{14}$ do trabalhador docente e a formação do professor nesses moldes deveria garantir a alienação pretendida e o controle da função da escola, necessidade posta no início do século XX, quando o capitalismo estava se consolidando no país e necessitava-se de mão de obra para o mercado de trabalho que estava se estruturando.

O trabalho constitui-se a atividade humanizadora do homem, por se considerar que $\mathrm{o}$ ato de produção e reprodução humana realiza-se pelo trabalho, pelas mudanças das relações com a natureza para sua sobrevivência. Para tanto, ele depende do trabalho não material, uma vez que [...] o homem necessita antecipar em ideias os objetivos da ação, o que significa que ele representa mentalmente os objetivos reais (SAVIANI, 2012, p. 12 ), 
ou seja, a produção do saber. Assim o trabalho docente, por ser um trabalho não material, é imprescindível para a realização do trabalho material, posto que

[...] os elementos culturais precisam ser assimilados pelos indivíduos da espécie humana para que se tornem humanos e, de outro lado e concomitante, à descoberta das formas mais adequadas para atingir esse objetivo (SAVIANI, 2008, p. 13).

A formação do trabalhador livre, aquele que irá realizar o trabalho material, deverá ser feita pelo trabalhador docente, que realiza o trabalho não material, na escola, instrumento para a legitimação e reprodução do sistema capitalista.

Desvirtuar o trabalho do docente do seu verdadeiro sentido, categoria fundante do indivíduo, transferindo para aspectos além da materialidade, é uma forma de aliená-lo, torná-lo estranho ao processo de humanização. É importante ressaltar que esta forma como a individualidade é instaurada, sob a perspectiva da visão de mérito e, consequentemente, gerando a competitividade, consiste em uma relação de estranhamento ao outro, na qual não se considera o outro como também trabalhador e professor e sim como uma ameaça. $\mathrm{O}$ trabalho alienado

Faz-lhe da vida genérica apenas um meio da vida individual. Primeiro, estranha a vida genérica, assim como a vida individual. Segundo, faz da última em sua abstração um fim da primeira, igualmente em sua forma abstrata e estranhada (MARX, 2008, p.84).

O processo de alienação se concretiza com a perda de autonomia do trabalhador docente e, como decorrência, há a perda de decisão, como, por exemplo, na imposição e aceitação de sua resignação.

$\mathrm{Na}$ introdução do Estado laico, a escola pública utiliza as práticas desencadeadas pelo modo cristão, nas quais a forma de "pregação" baseava-se não mais nos ícones da igreja, mas nos ícones da pátria, que, imaginariamente, comungam a comunhão cívica, "[...] que convoca os homens sensíveis e as almas de boa vontade a partilharem de uma sociedade composta de cidadãos [...]" (MONARCHA, 1999, p. 187).

O trabalhador docente foi convocado a edificar o civismo, uma forma de convencimento dos ideais liberais na sua versão republicana. Esse trabalhador tem "[...] muitas vezes necessidade de elevar o seu espírito à altura d'essa nobilíssima empresa" (PETRICH, 1906, p. 18), porém "não lhe é lícito sem sequer deixar transparecer suas crenças ou descrenças, $e$ os seus ensinamentos devem ser absolutamente indemes de sectarismo doutrinário" (COSTA, MOREIRA, SOUZA, 1910, p. 125). O liberalismo, utilizando-se das ideias de outras ideologias, como o positivismo, demonstra o seu lado conservador ao descartar qualquer manifestação religiosa, mas ao mesmo tempo utiliza-se do "culto" de outras formas de crenças, como a ideia de que o professor é "[...] na verdade o conctructor do edifício gigantesco da civilização" (A ESCOLA, 1907, p. 43).

Esse conservadorismo travestido, forçosamente imposto "[...] a partir de uma origem comum ou a partir da reificação de um inimigo comum" (VALLE, 1997, p. 119), caracteriza-se pelo culto ao civismo. Este se torna uma estratégia para a unificação do país, utilizando-se de vários elementos para o convencimento e conformação da sociedade, os quais podem ser verificados na Revista A Escola, ainda que de forma sutil. 


\section{Considerações Finais}

A carência de escolas para formação de professores no início do século XX possibilitou outros mecanismos refinados e eficazes para uma ampla divulgação dos ideais vigentes e para a homogeneização do trabalho desta categoria profissional mediante a uniformização do discurso pedagógico. A revista didática A Escola foi um desses instrumentos, uma vez que, estritamente direcionada aos professores, tornou-se uma forma eficaz e efetiva de manutenção dos ideais liberais. Um meio rápido de convencimento e coesão, ela era uma forma de propagação de ideias, canal de representação e, concomitantemente, de regulação, que, de modo sutil vinculava um sistema de ideias de como o real deveria ser compreendido e aceito.

O modelo ideal de trabalhador docente seria do respeitável sacerdote, resignado, sucessor secular do sacerdote, colocando-o tolerante ao seu papel de abnegado e omisso, suportando os seus desígnios sem arruídos e sem ameaçar a ordem. Sob esta ótica, há a exaltação dos aspectos morais sobre os intelectuais, desvirtuando o trabalho docente do seu verdadeiro sentido de categoria fundante do indivíduo, transferindo este para aspectos além da materialidade, colocando-o estranho ao processo de humanização, ou seja, alienando-o. Utilizando-se das práticas desencadeadas pelo modo cristão, o professor foi convocado a edificar o civismo, por intermédio dos ícones da pátria, uma forma de garantir a conciliação e a adesão à ideia de que a sociedade unificada republicana era ideal e harmônica. O discurso inflamado de bom cidadão, de amor à pátria era uma forma de disciplinamento. Daí a importância de um professor resignado a estes ditames e uma escola como fundamental para modelar condutas, tendo como elemento de manipulação o ideário de coesão nacional pelo viés do civismo.

O professor foi disseminador desses valores cívicos mediante um conjunto de artifícios no âmbito escolar, como, por exemplo, a valorização da língua pátria, amplamente divulgada na revista $A$ Escola. A valorização da língua, além de homogeneizar os cidadãos, era instrumento para impor valores, ideais e condutas não só aos nacionais como aos imigrantes, e a escola, bem como o trabalho docente foram eficazes para alcançar este objetivo.

\section{Referências:}

A ESCOLA: Revista do Grêmio dos Professores Públicos do Estado. 1906-1910. Curitiba: Acervo Biblioteca Pública do Paraná: divisão estadual.

ARAÚJO; J. C. Um capítulo da veiculação da discussão educacional na Imprensa doTriângulo Mineiro: a revista A Escola (1920-1921). In: ARAÚJO, José Carlos; GATTI Júnior, Décio (Orgs.). Novos temas em história da educação brasileira: instituições escolares e educação na imprensa. Campinas, SP: Autores Associados, 2002. p. 91-132.

BRAGA, C. Syntaxiologia. A ESCOLA, Revista do Grêmio dos Professores Públicos do Estado. Curitiba: Acervo Biblioteca Pública do Paraná: divisão estadual, 1910.

CAMBI, F. História da Pedagogia. Trad. Álvaro Lorencini. 3. reimpressão. São Paulo: Editora UNESP, 1999.

CARVALHO, M. M. C. Modernidade pedagógica e modelos de formação docente. São Paulo em Perspectiva, v. 14, n. 1, 2000. 
CORREIA, L. Termos de visita. A ESCOLA, Revista do Grêmio dos Professores Públicos do Estado. Curitiba: Acervo Biblioteca Pública do Paraná: divisão estadual, n. 4-5, p. 105, 1909.

COSTA, L; MOREIRA, F; SOUZA, L. Congresso dos professores Públicos: a todos os professores do Estado. A ESCOLA, Revista do Grêmio dos Professores Públicos do Estado. Curitiba: Acervo Biblioteca Pública do Paraná: divisão estadual, n. 6 p.104, 1906.

COSTA, B. Exames. A ESCOLA, Revista do Grêmio dos Professores Públicos do Estado. Curitiba: Acervo Biblioteca Pública do Paraná: divisão estadual, n. 10-11 p.172, 1906.

DIAS, E. F. O liberalismo e a invenção da tradição. In: LOMBARDI, José Claudinei; SANFELICE, José Luís (Orgs.). Liberalismo e educação em debate. Campinas, SP: Autores Associados, HISTEDBR, 2007. p. 115-130.

GOMES, R. Asumptos pedagogicos. A ESCOLA, Revista do Grêmio dos Professores Públicos do Estado. Curitiba: Acervo Biblioteca Pública do Paraná: divisão estadual, n. 6-7 p23-34, 1909.

GOMES, R.R. A Escola e o Cidadão. A ESCOLA, Revista do Grêmio dos Professores Públicos do Estado. Curitiba: Acervo Biblioteca Pública do Paraná: divisão estadual, n. 6-7 p. 94, 1907.

HOBSBAWM, Eric. RANGER, Terence. A invenção das tradições. Rio de Janeiro: Paz e Terra, 1984.

LOCKE, J. Carta sobre a tolerância. São Paulo: Hedra, 2007.

LOCKE, J. Ensaio acerca do entendimento humano. Segundo tratado sobre o governo. 5. ed. São Paulo: Nova Cultural, 1991. (Os pensadores).

LOCKE, J. Pensamientos sobre la educación. Prólogo de Mariano Enguita. Madri: Akal, 1986.

MACEDO, A. Epístolas Pedagógicas. A ESCOLA, Revista do Grêmio dos Professores Públicos do Estado. Curitiba: Acervo Biblioteca Pública do Paraná: divisão estadual, n.1, p. 10-11, 1906.

MARACH, C. B. Inquietações modernas: discurso educacional e civilizacional no periódico A Escola (1906-1910). Dissertação (Mestrado em Educação) - Universidade Federal do Paraná, Curitiba, 2007.

MARX, Karl; ENGELS, Friedrich. A ideologia alemã I. Lisboa: Presença, 1979.

MARX, K. Contribuição à crítica da economia política. Trad. Maria Helena Barreiro Alves; revisão Carlos Roberto f. Nogueira. 2. ed. São Paulo: Martins Fontes, 1983.

MARX, K. Manuscritos econômicos filosóficos e outros textos escolhidos. Seleção de textos de José Arthur Giannotti; traduções de José Carlos Bruni ET al. 5. ed. São Paulo: Nova Cultural, 1991. (Os pensadores).

MARX, K. Manuscritos econômicos e filosóficos. Tradução, apresentação e notas de Jesus Ranieri. São Paulo: Boitempo, 2008.

MONARCHA, C. Escola Normal da Praça: o lado noturno das luzes. Campinas, SP: Editora Unicamp, 1999.

NAGLE, J. Educação e sociedade na primeira República. 3. ed. São Paulo: EPU/MEC; EDUSP, 2009. 
PARANÁ. Regulamento de Instrução Pública do Estado do Paraná, 11 de março de 1901. Curitiba: Arquivo Público do Paraná, 1901.

PARANÁ, S. A Escola. A ESCOLA, Revista do Grêmio dos Professores Públicos do Estado. Curitiba: Acervo Biblioteca Pública do Paraná: divisão estadual, n. 1 p.1-2, 1906.

PARANÁ, S. Epístolas Pedagógicas. A ESCOLA, Revista do Grêmio dos Professores Públicos do Estado. Curitiba: Acervo Biblioteca Pública do Paraná: divisão estadual, n. 56, P. 135-137, 1906.

PARANÁ, E.F A Escola. A ESCOLA, Revista do Grêmio dos Professores Públicos do Estado. Curitiba: Acervo Biblioteca Pública do Paraná: divisão estadual, 1906.

PETRICH, J.V. Relatórios. A ESCOLA, Revista do Grêmio dos Professores Públicos do Estado. Curitiba: Acervo Biblioteca Pública do Paraná: divisão estadual, n. 1 p.17-25, 1906.

PONCE, A. Educação e luta de classes. Trad. José Severo de Camargo Pereira. 18. ed. São Paulo: Cortez, 2001.

SAVIANI, D. Pedagogia histórico-crítica: Primeiras aproximações polêmicas do nosso tempo. 11. ed. São Paulo. Autores associados, 2008.

SOUZA, L. A Missão da Escola. A ESCOLA, Revista do Grêmio dos Professores Públicos do Estado. Curitiba: Acervo Biblioteca Pública do Paraná: divisão estadual, n. 1, p.1-5, 1906.

SOUZA, L. Relatório. A ESCOLA, Revista do Grêmio dos Professores Públicos do Estado. Curitiba: Acervo Biblioteca Pública do Paraná: divisão estadual, n. 4, p. 82, 1906.

SOUZA, R. F. Lições da escola primária. In: SAVIANI, Dermeval et al. O legado educacional do século XX no Brasil. 2. ed. Campinas, SP: Autores Associados, 2006. p. 109-151- ( Coleção Educação Contemporânea).

VALDEMARIN, V. T. Liberalismo demiurgo: estudo sobre a reforma educacional projetada nos Pareceres de Rui Barbosa. São Paulo: Cultura Acadêmica, 2000.

VALLE, L. A escola e a nação: as origens do projeto pedagógico brasileiro. São Paulo: Letras \& Letras, 1997.

VELlOZO, D. Subsídios Pedagógicos. A ESCOLA, Revista do Grêmio dos Professores Públicos do Estado. Curitiba: Acervo Biblioteca Pública do Paraná: divisão estadual, 1906.

\footnotetext{
1 Professora da Rede Municipal de Ensino de Irati-PR. Doutora em Educação: História e Políticas educacionais pela Universidade Estadual de Ponta Grossa-UEPG. Contato aecmari@ gmail.com.

${ }^{2}$ Professora Adjunta D da Universidade Estadual de Ponta Grossa-UEPG, Pós-Doutorado em História e Filosofia da Educação pela Universidade Estadual de Campinas-UNICAMP. Contato: misabel@lexxa.com.br

${ }^{3}$ A ESCOLA: Revista do Grêmio dos Professores Públicos do Estado, 1906-1910. Acervo Biblioteca Pública do Paraná: divisão estadual,. As revistas estão encadernadas e disponíveis para pesquisa. Os escritos desta fonte primária estarão em letras itálicas e na grafia original. Para saber mais sobre esse periódico ver Marach (2007).

${ }^{4}$ O Grêmio foi uma organização de docentes do Estado do Paraná, que buscava promover debates sobre assuntos referentes à educação, visando "a fraternização e progredimento espiritual dos membros da nobre classe do professorado paranaense" (ESCOLA, 1907, n, 1-4, p. 43). Para ser sócio o professor deveria contribuir com a quantia de dois mil réis mensal para o Grêmio. (MARACH, 2007, p. 83)
} 
5 A autora Carvalho (2000) apresenta esse período como da Pedagogia Moderna ou Pedagogia Hodierna. Embora o termo seja utilizado no período deste estudo, inclusive pelos articulistas da Revista A Escola, considera-se que o período foi de consolidação da Pedagogia Liberal, e que a própria indumentária de pedagogia moderna era uma forma de sedução para os preceitos liberais.

${ }^{6}$ Conforme este Regulamento, artigo 62, inciso 11, o professor deverá “dirigir ao director-geral, por intermédio dos inspectores escolares, no fim de cada ano, um relatório sobre o estado de suas escolas e adiantamento de seus alumnos, acompanhado de um mapa em que figurem todos ellles, com as declarações sobre cada um" (PARANÁ, 1901, p. 101).

7 Do latim promiscuu, que significa misturado, as cadeiras promíscuas indicavam as escolas mistas, em que frequentavam alunos de ambos os sexos.

${ }^{8}$ A numeração das páginas era contínua, não encerrando a cada publicação.

9 Os profissionais dessa revista tinham uma formação eclética: médicos, geógrafos, historiadores, professores, advogados.

10 A expressão "papel em branco", cunhado por Locke (1991), significa que, ao contrário do que autores como Descartes propunham, qual seja que os homens possuem ideias inatas, para este teórico as ideias originam-se da experiência. "Todo conhecimento está nela fundado e dela deriva fundamentalmente o próprio conhecimento" (LOCKE, 1991, p. 27).

${ }^{11}$ A felicidade e a desgraça do homem são, em grande parte, sua própria obra.

12 À escola foi depositada a finalidade de formar os novos cidadãos, referindo-se assim a uma regeneração da Nação brasileira, que, até então, estava sob o crivo dos moldes obsoletos dos valores do Império.

13 Para saber mais sobre o termo "invenção da tradição" ler: HOBSBAWM, Eric. RANGER, Terence. A invenção das tradições. Rio de Janeiro: Paz e Terra, 1984.

14 Considera-se alienação quando o indivíduo se torna alheio, estranho à sua própria atividade, sem consciência da exploração a qual é submetido, por essa ser considerada como algo natural.

Recebido: maio-15 aprovado: agosto-15 